\title{
Management of Arrhythmias Associated with COVID-19
}

\author{
Accepted: 11 November 2020 / Published online: 24 November 2020 \\ (C) Springer Science+Business Media, LLC, part of Springer Nature 2020
}

Amar D. Desai ${ }^{1} \cdot$ Brian C. Boursiquot $^{1} \cdot$ Lea Melki $^{1} \cdot$ Elaine Y. Wan $^{1,2}$ (D)

\begin{abstract}
Purpose of Review Cardiac arrhythmias are known complications in patients with COVID-19 infection that may persist even after recovery from infection. A review of the spectrum of cardiac arrhythmias due to COVID-19 infection and current guidelines and assessment or risk and benefit of management considerations is necessary as the population of patients infected and covering from COVID-19 continues to grow.

Recent Findings Cardiac arrhythmias such as atrial fibrillation, supraventricular tachycardia, complete heart block, and ventricular tachycardia occur in patients infected, recovering and recovered from COVID-19.

Summary Personalized care while balancing risk/benefit of medical or invasive therapy is necessary to improve care of patients with arrhythmias. Providers must provide thorough follow-up care and use necessary precaution while caring for COVID-19 patients.
\end{abstract}

Keywords Sars-CoV-2 · COVID-19 · Cardiac arrhythmias

\section{Introduction}

SARS-CoV-2, the severe acute respiratory syndrome coronavirus 2, responsible for COVID-19, has infected over 37 million people globally and almost 8 million people in the USA alone [1]. While the primary symptoms of COVID-19 may be respiratory in nature for the vast majority of cases, several studies have pointed to extrapulmonary effects of the virus [2]. This phenomenon is likely observed due to the cumulative effects of the hyperinflammatory response of the body and the omnipresence in major organs of the angiotensin-converting

This article is part of the Topical Collection on Invasive Electrophysiology and Pacing

Elaine Y. Wan

eyw2003@cumc.columbia.edu

Amar D. Desai

add2160@cumc.columbia.edu

Brian C. Boursiquot

brb9137@nyp.org

Lea Melki

1m3088@cumc.columbia.edu

1 Division of Cardiology, Department of Medicine, Vagelos College of Physicians and Surgeons, New York-Presbyterian/Columbia University Irving Medical Center, New York, NY, USA

2 Cardiology and Cardiac Electrophysiology, Columbia University, 177 Fort Washington Avenue, New York, NY 10032, USA enzyme 2 (ACE2) cellular receptor that SARS-CoV-2 uses for cell entry [3]. Of all systems which may be affected by the virus, possibly the most common extrapulmonary complications can be observed in the cardiovascular system, with these complications including myocardial injury, cardiomyopathy, acute coronary syndrome, cardiogenic shock, acute cor pulmonale, thrombotic complications, and arrhythmias $[4 \bullet \bullet, 5]$.

Herein, we describe the signs, symptoms, and pathophysiology of cardiac arrhythmia in COVID-19 (Table 1). SARS-CoV2 infection may cause deleterious cardiovascular effects manifested as cardiac enzyme release and a heightened systemic inflammatory response, which has noted to include elevations in ferritin, lactate dehydrogenase (LDH), C-reactive protein (CRP), and interleukin-6 (IL-6) [6]. The mechanism of myocardial injury may be secondary to the immune response, elevated catecholamine, hypercoagulable state, and/or directly due to myocyte viral invasion $[7,8]$. Indeed, post-mortem pathological studies have discovered myocardial tissue positive for SARSCoV-2 by reverse transcription polymerase chain reaction (RTPCR) and electron microscopy [9]. However, there have been no detailed reports to date of post-mortem virus that have evaluated if those patients who died of a cardiac arrhythmia had viral infection in the cardiac conduction tissue such as the HisPurkinje system. The high incidence of arrhythmias in COVID-19 is thought to be multifactorial: hypoxemia due to acute respiratory distress, acute decline in cardiac hemodynamics, myocarditis, cardiac injury, prominent inflammatory 
Table 1 Symptoms, clinical findings, and pathophysiology of cardiac arrhythmias during and after COVID-19 infection

\begin{tabular}{|c|c|c|}
\hline Arrhythmia & Symptoms and clinical findings & Pathophysiology \\
\hline AF/AFL & $\begin{array}{l}\text { - Palpitations } \\
\text { - Dizziness } \\
\text { - Chest discomfort } \\
\text { - Fatigue } \\
\text { - Stroke/thromboembolism } \\
\text { - Heart failure }\end{array}$ & $\begin{array}{l}\text { - Systemic inflammation } \\
\text { - Worsening of pre-existing } \\
\text { cardiovascular disease }\end{array}$ \\
\hline SVT & $\begin{array}{l}\text { - Palpitations } \\
\text { - Dizziness } \\
\text { - Chest discomfort } \\
\text { - Fatigue }\end{array}$ & $\begin{array}{l}\text { - Systemic inflammation } \\
\text { - Worsening of pre-existing } \\
\text { cardiovascular disease }\end{array}$ \\
\hline $\mathrm{VT} / \mathrm{VF}$ & $\begin{array}{l}\text { - Syncope } \\
\text { - Sudden cardiac death }\end{array}$ & $\begin{array}{l}\text { - Myocarditis } \\
\text { - Acute myocardial infarction } \\
\text { - Systemic inflammation } \\
\text { - Worsening of pre-existing } \\
\text { cardiovascular disease } \\
\text { - QT prolongation }\end{array}$ \\
\hline AV Block & $\begin{array}{l}\text { - Dizziness } \\
\text { - Fatigue } \\
\text { - Complete heart block } \\
\text { - Asystole }\end{array}$ & $\begin{array}{l}\text { - Unclear if reversible } \\
\text { - Unclear if due to inflammation, } \\
\text { or direct injury } \\
\text { of AV node or His-Purkinje system, } \\
\text { or worsening } \\
\text { of pre-existing conduction disease }\end{array}$ \\
\hline POTS/IAST & $\begin{array}{l}\text { - Palpitations } \\
\text { - Dizziness } \\
\text { - Fatigue } \\
\text { - Tachycardia at rest and } \\
\text { worse with activity }\end{array}$ & - Autonomic dysfunction \\
\hline QTc prolongation & - May lead to TDP & $\begin{array}{l}\text { - QT prolonging medications } \\
\text { - Myocardial injury } \\
\text { - Structural heart disease, } \\
\text { - Electrolyte disturbance } \\
\text { - Renal dysfunction }\end{array}$ \\
\hline
\end{tabular}

response, direct viral invasion, and/or use of QT prolonging medications [10-12].

Early reports from Wuhan showed that $44 \%$ of patients admitted to the intensive care unit with COVID-19 had arrhythmias, raising initial suspicions of arrhythmias associated with COVID-19 [13]. We discuss in this manuscript a perspective on the arrhythmia associated with COVID-19 and their management considerations (Fig. 1 and Table 2).

\section{Atrial Arrhythmias}

Atrial arrhythmias are the most commonly reported arrhythmias in patients with COVID-19. Similarly, atrial fibrillation (AF)- related consultations were the most common electrophysiology consultations during the peak of the pandemic in New York City at Columbia University for COVID-positive patients (31\%), with only $13 \%$ of these COVID-positive patients having a history of AF [14]. In stark contrast with a typical AF population, none of these COVID-19 patients with new-onset atrial tachyarrhythmia had a history of cardiac surgery, ablation, cardioversion, or antiarrhythmic drug-use. The etiology of these atrial arrhythmias is yet to be fully understood, but proposed theories include alterations in ACE2-related signaling pathways, inflammation, direct viral endothelial damage, and metabolic derangements during the acute illness [15].

Notably, AF has been associated with worse outcomes in patients who have acute respiratory disease. Prior to the 
Fig. 1 Cardiac arrhythmias during and after COVID-19 infection. This figure illustrates the effects of COVID-19 infection on the cardiac conduction system, the spectrum of cardiac arrhythmia, and possible management considerations

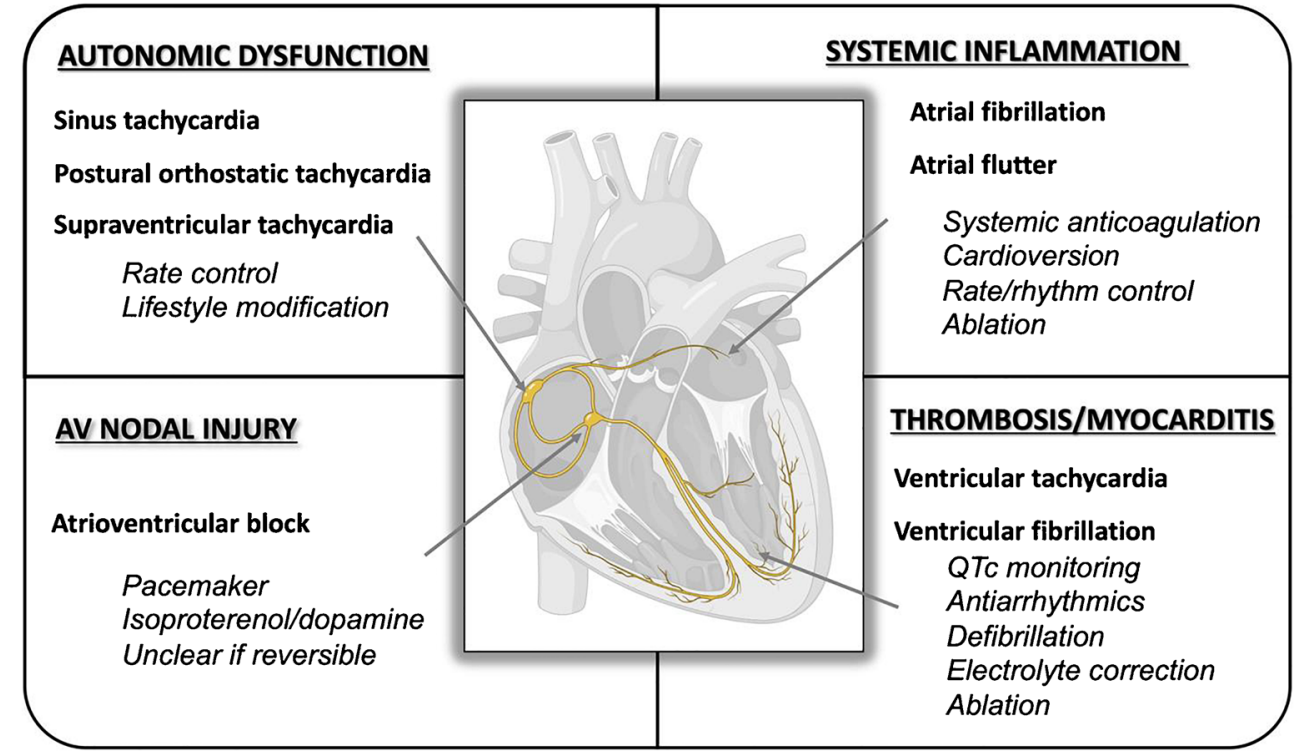

COVID-19 era, patients with new-onset AF during acute respiratory syndrome (ARDS) and severe pneumonia had increased mortality compared to those ARDS patients without new AF [16]. In Columbia University's aforementioned consultation experience, $55 \%$ of patients in the small sample of nine expired by the end of the study, with the remaining hospitalized, reflecting the poor prognosis of patients with new onset of AF during COVID-19 infection [14]. In another study, atrial arrhythmias were also more common among patients who needed mechanical ventilation ( $17.7 \%$ vs. $1.9 \%$ otherwise) [17]. These studies highlight the importance of careful management considerations for these patients, especially those with new-onset AF.

AF is typically treated with rate or rhythm control and also with anticoagulation in patients who meet criteria and do not have contraindications due to bleeding risk [18]. For rate control, pharmacological management with diltiazem in patients with COVID-19 seemed to be common since there is concern that beta-blockers may cause bronchospasm during respiratory illness [19] (Table 2). In COVID-19 patients with newonset AF, Columbia University's study reported the use of amiodarone in $29 \%$ of patients referred for electrophysiology consultation, with anticoagulant usage reported in $83 \%$ [14]. It is unclear if early detection and treatment of COVID-19 may mitigate such arrhythmic cardiac complications. Furthermore, it is unclear if prophylactic use of antiarrhythmics in COVIDpositive patients at risk of cardiac complications should be considered earlier on in the treatment, due to the increase in mortality in patients with arrhythmia [20].

\section{Ventricular Arrhythmias}

In contrast to atrial arrhythmias consisting of $31 \%$ of electrophysiology consults at the peak of the pandemic, ventricular arrhythmias made up a significantly smaller $7 \%$ of consults at the Columbia University Medical Center [14]. Structural heart disease has historically been shown to be a risk factor for ventricular arrhythmias [21]. We have previously reported ventricular tachycardia (VT) and ventricular fibrillation (VF) as the primary cause of death in COVID-19 patients without a prior history of structural heart disease [22]. However, this could be due to the association of ventricular arrhythmias in patients who are critically ill [23].

Several studies investigating cardiac arrhythmia most proximate to death for patients infected with COVID-19 describe VT and VF in $6 \%$ of deaths $[24,25]$. Notably, the majority of COVID-19 deaths had asystole or pulseless electric activity (PEA) at time of death, likely due to respiratory failure or pulmonary embolism [21]. VT/VF may also be due to cardiac ischemia or acute myocardial infarction as there have been studies suggesting increased thromboembolism in COVID-19 [26-28]. Furthermore, patients with myocarditis due to COVID-19 may have increased risk for sudden cardiac death although it is unclear how to risk stratify these patients [27-29].

The usage of antiarrhythmics for prophylaxis of VT/VF for patients during COVID infection is unclear, especially since it is still not known why some patient have cardiac arrhythmic complications and others do not. Usage of QT prolonging drugs, such as amiodarone, presents a possible risk of torsades de pointes (TDP) and nodal agents may cause bradycardia (Table 2) [30•].

\section{VT Storm}

Ventricular arrhythmias that arise in COVID-19 patients may lead to VT storm defined as 3 or more hemodynamically stable ventricular tachyarrhythmias in $24 \mathrm{~h}$, VT recurring after 
Table 2 Management of cardiac arrhythmias in patients with and without COVID-19 infection

Standard-of-care management in patients without COVID-19

Management considerations in setting of COVID-19 infection

Atrial tachyarrhythmias

Atrial fibrillation [18]

- First-line rate control consists of beta-blockers and/or non-dihydropyridine calcium channel blockers.

- In hypotensive patients, amiodarone may be used.

- Cardioversion can be used in hemodynamically unstable atrial fibrillation

- Rhythm control may be preferred, especially in symptomatic patients. Antiarrhythmic drugs (most commonly flecainide, dofetilide, propafenone, ibutilide, and amiodarone) may be used as pre-treatment for electric cardioversion, for pharmacologic cardioversion, or for chronic maintenance of sinus rhythm.

- Catheter ablation may be chosen after failure/intolerance of drugs, or initially by preference. Surgical ablation may be considered in patients with other indications for cardiothoracic surgery.

- For prevention of thromboembolism, anticoagulation is indicated peri-procedurally for cardioversion and ablation, as well as long-term for $\mathrm{CHA}_{2} \mathrm{DS}_{2}$-VASc score $\geq 2$ in men or $\geq 3$ in women. In patients at high risk for bleeding with long-term anticoagulation, occlusion or exclusion of left atrial appendage may be considered.

Inappropriate sinus tachycardia

- Reassurance and lifestyle interventions including exercise and avoidance of cardiac stimulants.

- Beta-blockers and/or ivabradine may be used in symptomatic patients [48]

- Sinus node ablation may be considered in refractory cases.

- Patients with underlying restrictive pulmonary disease or chronic obstructive pulmonary disease should be cautioned for bronchospasm while on beta-blocker therapy.

- Caution should be used for amiodarone in patients with decreased pulmonary function and/or fibrotic lung disease after COVID-19.

- During aerosolizing procedures such as intubation or transesophageal echocardiogram, healthcare providers should don appropriate personal protective equipment.

- Cardiac computed tomography may be considered as an alternative imaging modality for evaluation of thrombus prior to cardioversion if patient is actively infected with COVID-19. [83, 84]

- Given the high rates of thrombotic complications in COVID-19 [4••], the indications and duration of anticoagulation are unclear.

Postural orthostatic tachycardia syndrome

- Initial management includes consumption of 2-3 L/day of water and - Tilt-table testing may be considered for evaluation for POTS.

10-12 g/day of sodium, as well as regular and progressive exercise. • Patients with COVID-19 and evidence of myocardial injury or inflammation should

- Fludrocortisone may be used to aid sodium and water retention.

- Midodrine or pyridostigmine may be considered.

- Low-dose propranolol or ivabradine may be considered [54].

Other supraventricular tachycardia

- Cardioversion is indicated in unstable patients.

- Vagal maneuvers may abort episodes of AVRT/AVNRT.

- Adenosine may be used for abortion or to slow rhythm and aid diagnosis

- Management varies depending on specific arrhythmia.

Therapies commonly include beta-blockers and non-dihydropyridine calcium channel blockers, among other antiarrhythmic drugs.

- Catheter ablation may be efficacious.

- Electrophysiologic studies may be used for diagnosis or to guide therapy.

Atrioventricular block

- Avoidance of AV nodal blockade is prudent in all types.

- First-degree AV block generally does not require management.

- For second and third degree, stabilization (e.g., with atropine or

transvenous pacing) and evaluation for reversible causes is the first step.

- Permanent pacemaker is indicated if symptomatic,

or in those with second degree type II or third degree blocks.

Ventricular arrhythmias

- Beta-blockers and/or antiarrhythmics.

- ICDs for primary and secondary prevention.

- Magnesium, isoproterenol or ventricular pacing should be considered in TDP.

- Catheter ablation.

Electrical storm

- If unstable, patients should be treated with defibrillation.

- Initial therapy consists of both intravenous antiarrhythmic agents (generally amiodarone; but procainamide, flecainide, or lidocaine is also used) and beta-blockers.

- Urgent coronary revascularization is indicated in patients with active myocardial ischemia.

- Urgent catheter ablation is indicated in medically refractory cases or in scar-related disease.

- Antiarrhythmic therapy may be continued long term, especially in patients who do not undergo ablation.

- As in the general population, other etiologies of sinus tachycardia must be excluded. Pulmonary embolism should be considered in patients with unexplained sinus tachycardia

- Outpatient Holter or event monitor may be helpful for diagnosis.

- Beta-blockers may be considered.

- It is unclear whether ivabradine may be useful.

defer competitive sports or aerobic exercise until 3-6 months following infection and resolution of imaging findings and normalization of troponin $[55,56 \bullet \cdot]$.

- Anticoagulation is generally not indicated unless atrial fibrillation is also present, but in patients with COVID-19, further study may be needed.

- Catheter ablation may be considered.

- Outpatient Holter or event monitor may be helpful for diagnosis.

- Pacemaker placement for complete heart block, symptomatic bradycardia, and high-degree AV block.

- The necessity of secondary prevention ICDs is unclear, as patients with COVID-19 and ventricular arrhythmias may have no evidence of structural heart disease [22], and acute infection may be considered a reversible precipitant.

- In patients who do not undergo catheter ablation, the risk of recurrent arrhythmias after resolution of COVID-19 is not known. 
termination of another episode, or sustained and nonsustained VT episodes exceeding normal beats within $24 \mathrm{~h}$. Antiarrhythmic drug therapy may be effective using amiodarone and beta-blockers [31] but may require deep sedation and hemodynamic support as well [32]. For COVID-19 patients suffering from a VT storm, case studies of patients with newonset ventricular arrhythmias have also shown the efficacy of substrate-based VT catheter ablation procedures if implantable cardioverter defibrillator (ICD) shocks prove futile. These case studies report patient recovery from COVID-19 without further ICD interventions [33]. While the sample size is small, these ablation case studies may offer a promising alternative to the difficulties in applying proper drugtherapies to COVID-19 patients. Possible long-term effects of aggressive ablation strategy in a COVID-19 specific population are yet to be observed.

\section{Atrioventricular Block}

Atrioventricular (AV) block may account for up to $12 \%$ of arrhythmias seen in patients with COVID-19 [34]. While the mechanism behind this observation is not certain, heart block can be a manifestation of myocarditis [35], and myocarditis has been associated with the infection [8]. Although several cases of COVID-19-related AV block have been reported in patients with preserved ventricular function and/or normal cardiac biomarkers [36-38], it is possible that these cases otherwise represent subclinical myocardial inflammation. In one such case, cardiac magnetic resonance imaging (MRI) revealed ventricular wall edema suggestive of myocarditis despite no evidence of myocardial injury [36]. Moreover, AV block seen in the setting of acute infection can resolve spontaneously [39, 40]. Patients with COVID-19 and persistent high-grade AV block have been managed with standard-ofcare pacemaker placement and outpatient follow-up (Table 2) [36-38]. However, the development of heart block in patients with COVID-19 has been suggested to be a poor prognostic sign, with many of the reported cases occurring in patients who ultimately succumbed to the disease [40-43].

\section{Inappropriate Sinus Tachycardia}

The incidence of inappropriate sinus tachycardia (IST) in patients with COVID-19 is uncertain. By definition, IST is a diagnosis of exclusion. Therefore, it is very unlikely to be diagnosed in the setting of acute infection as patients with hypoxemia may be in sinus tachycardia. Persistent tachycardia after infection may represent as IST and has been shown in patients recovering from SARS, suggesting it may be seen in patients recovering from COVID-19 as well [44, 45]. The mechanism of IST is likely multifactorial including intrinsic sinus node hyperactivity, autonomic dysfunction, and a hyperadrenergic state [46•]. Inflammatory cytokines released by patients with COVID-19 may affect the function of myocardial ion channels and perpetuate tachyarrhythmia including sinus tachycardia [47]. Ongoing symptomatic IST may be treated with beta-blockers and/or ivabradine (Table 2) [48], although treatment efficacy is unknown in patients with COVID-19. It is of note that ivabradine usage in IST is not FDA approved and is off label.

\section{Postural Orthostatic Tachycardia Syndrome}

Postural orthostatic tachycardia syndrome (POTS) is caused by autonomic dysfunction; the underlying mechanism of which may be related to peripheral neuropathy, increased serum norepinephrine, baroreceptor dysfunction, or hypovolemia [49, 50]. The syndrome has previously been reported to develop after acute stressors including viral illness and, therefore, may also develop in some patients recovering from COVID-19 [49-51]. Furthermore, dysautonomia including postural tachycardia have already been reported in COVID-19 patients [52, 53]. Nonpharmacologic management of POTS includes increasing salt and fluid intake, use of lower extremity compression garments to reduce venous pooling, and participation in regular exercise to prevent deconditioning [54]. However, patients with COVID-19 and evidence of myocardial injury or inflammation should abstain from competitive sports or aerobic activity until resolution of imaging findings or normalization of cardiac biomarkers $[55,56 \bullet \cdot$. When these measures are ineffective, various pharmacologic therapies may be attempted depending on the specific etiology suspected. These therapies include fludrocortisone, midodrine, pyridostigmine, propranolol, ivabradine, and alpha-2 agonists [54]. Ivabradine prescription for treatment of POTS is not FDA approved and is off label. Patients with COVID-19 may benefit from low-dose propranolol for lowering heart rate and reducing adrenergic activity (Table 2) [57].

\section{Pediatric Considerations}

While immediate treatment-requiring arrhythmias in children are often extremely rare, pediatric patients most commonly report supraventricular tachycardias. The latter are often carefully treated with a combination of both pharmacotherapy such as amiodarone, ibutilide, beta-blockers, or cardioversion [58]. The American Heart Association released guidelines in collaboration with the American Academy of Pediatrics as to treatment of children and infants with COVID-19. Within these guidelines, they suggest for pediatric patients suffering from life-threatening arrhythmias, early usage of endotracheal tubes/ventilation, and defibrillation [59]. That said, apart from 
COVID-19 case studies which primarily report increased risk for pediatric patients with prior history of cardiac surgery, limited data are available for children with COVID-19 at this time of writing [60].

\section{Myocarditis}

Myocarditis is a leading cause for the development of ventricular arrhythmias [14]. Myocarditis has also been presented as the most probable cause of myocardial injury and has been observed in 7.2-27.8\% of COVID-19 patients [5]. While it may not be possible to fully rule out prior silent ischemia in these patients, myocarditis may be a more likely culprit, due to direct viral infection of cardiomyocytes, hypoxia, or hyperimmune response [22]. Autopsies on COVID-19 patients with myocarditis have shown direct invasion by the virus and inflammatory processes in the tissue without any presence of COVID-19 [61, 62]. Although the exact etiology of myocarditis remains in question, management of myocarditis for COVID-19 patients has shown relatively favorable outcomes in patients treated with glucocorticoid therapies [63]. Furthermore, in accordance with possibilities of hyperimmune response and hypoxia, second-line agents such as IL-6 inhibitors and intravenous immunoglobulin (IVIG) were often administered with or without vasopressor support [63]. Large-scale studies have yet to show the efficacy of glucocorticoid therapies on the heart for COVID-19 patients and their use remains controversial, with several studies suggesting these therapies have no or a harmful effect on patients [64]. Optimal dosing guided by ARDS sub-phenotypes, biomarkers, and comorbidities should be utilized before administration of glucocorticoids for COVID-19 patients with myocarditis [65].

\section{Cardiac Arrhythmias During and After Recovery}

Given the recent onset of the COVID-19 pandemic, data on longterm cardiovascular outcomes in patients who have recovered are lacking. Patients who developed overt cardiac disease should receive regular monitoring and reassessment. For those diagnosed with arrhythmias in the acute setting, it is plausible that some of these may resolve during convalescence. Therefore, the optimal duration of therapy should be personalized and made according to the patient and physician's discretion.

Risk stratification may be helpful to guide monitoring during recovery, with further testing indicated in those with cardiac involvement during infection. It has been proposed that patients with any evidence of possible myocardial injury should undergo follow-up transthoracic echocardiogram (TTE) and electrocardiogram (EKG) 2-6 months after COVID-19 diagnosis [66]. Holter or event monitoring should be used as indicated by symptoms, but it may also be reasonable to consider their use in asymptomatic patients, given the risk of a variety of arrhythmias in patients with COVID19 (Table 2). Abnormal findings on TTE, EKG, or cardiac monitoring should trigger additional investigation, which may include stress testing or cardiac MRI. The role of cardiac MRI after COVID-19 infection has been controversial as it is more sensitive than initial screening tests and may reveal findings of unclear clinical significance. In a study of 100 COVID-19-recovered patients, 60 had evidence of myocardial inflammation, 32 had myocardial late gadolinium enhancement (including 12 patterns suggestive of ischemia), and 22 had pericardial enhancement [67]. Finally, three patients had severe abnormalities that were followed up with endomyocardial biopsy, ultimately revealing active lymphocytic inflammation.

Due in part to evidence of subclinical myocarditis seen in these patients, there is concern that COVID-19 infection may declare itself as a risk factor for heart failure in the long term [68]. As more data is obtained, cost-effectiveness analyses of testing in the recovery period may be considered, as well as randomized trials of prophylactic therapy for arrhythmias and/ or myocardial dysfunction [66]. Cardiac MRI may be helpful for risk stratification and to guide counseling on return to aerobic exercise or competitive sports. It has been proposed that COVID-19 patients who have ever had symptoms should rest for at least 2 weeks and undergo initial testing similar to that described above [69]. Given the absence of COVID-19specific data, patients with evidence of cardiac involvement should follow the guidelines for athletes with myocarditis and defer resumption of activity for 3-6 months [55, 56・•, 69].

Management of patients after long-term COVID-19 recovery is even more uncertain. Patients who recovered from SARS were shown to have more hyperlipidemia, cardiovascular disorders, and impaired glucose metabolism at 12-years of follow-up compared to age-matched controls [70]. Findings of the same study suggest that recovered SARS patients have altered lipid metabolism due to steroid use during their infection. It is plausible that similar findings may be seen in patients who are recovered from COVID-19, especially if they were also treated with steroids for severe pneumonia. At minimum, these patients should undergo age-appropriate cardiovascular disease screening in a primary care setting. However, more intensive screening may be considered.

\section{Monitoring of Corrected QT Interval (QTc)}

The use of QTc-prolonging drugs, including hydroxychloroquine (HCQ) and azithromycin (AZ), in the treatment of COVID-19 infection was forced into the limelight after a small, nonrandomized study of 36 patients suggested that HCQ alone or added to AZ aided clearance of a positive nasopharyngeal virus sample [71]. This study was the foundation for the rapid adaptation 
of HCQ and/or AZ in worldwide clinical practice for COVID-19. Prolongation of the QT interval is a known risk factor for sudden cardiac death due to ventricular cardiac arrhythmias such as TDP $[72,73]$. A previous study has reported significantly elevated risk of cardiac arrest in COVID-19 patients receiving HCQ + AZ, as well as in nonventilated COVID-19 patients receiving HCQ alone [74]. The known effect of HCQ and AZ on prolongation of the QT interval has led to many subsequent studies on incidence of TDP and sudden cardiac death in COVID infection. Due to these risks and evidence that the regimen lacks efficacy [75-77], these drugs are no longer used to treat COVID-19.

The direct causes of QT prolongation by HCQ and AZ are due to inhibition of the rapid delayed rectifier potassium current $\left(I_{\mathrm{Kr}}\right.$, or hERG) [78, 79]. However, indirect causes of QT prolongation in COVID infection may include inflammation, renal dysfunction, new onset of cardiac disease, electrolyte imbalance, and usage of other additional QTc-prolonging drugs.

Previous studies have suggested that increase in cytokines, such as IL-6, may prolong QT in patients with viral infection. HIV-associated inflammation, causing elevated IL-6, has been shown to be independently associated with QT prolongation [80] and prolonged repolarization represented as T wave onset-to-peak duration [81]. HIVpositive patients had longer QTc intervals and QTc prolongation often $>500 \mathrm{~ms}$, even after taking into account other QT prolonging drugs like methadone when compared to HIV negative patients [82].

\section{Conclusions}

The true prevalence of cardiac events in patients with COVID-19 may not be fully appreciated. This review highlights the cardiac arrhythmias - such as AF, AV block, IST, POTS, and VT/VF-during and after COVID-19 infection (Fig. 1), underscoring the importance of careful cardiac management considerations in COVID-19 patients. Furthermore, given the breadth of cardiac arrhythmias involved in COVID-19 and the diversity of their etiologies, remote digital monitoring has emerged as a growing and necessary aspect of COVID-19 management for patients with cardiac complications or at risk of cardiac complications. With the onset of new therapeutics for COVID-19, further questions are raised as to how this will impact the management of arrhythmias. Studies will be needed to investigate the association between vaccination-status and risk of COVID-19-related cardiac arrhythmias. Furthermore, future research is needed to determine whether vaccination may be protective of cardiac injury and development of cardiac arrhythmias and which patients would most derive benefit. Similarly, with monoclonal antibody treatment recently gaining increased attention, it remains unknown what cardiac management changes would accompany widespread adoption of these types of treatment. Finally, with subsequent waves of COVID-19 approaching, or already starting in many parts of the country, little is known on how re-infection, a second course of infection, will affect previously infected individuals. The exact cardiac complications which may accompany a second COVID-19 infection are yet unknown.

Funding E.Y.W. is supported by the NIH R01 HL152236, R03 HL146881, the Louis V. Gerstner, Jr. Scholar Program and the Esther Aboodi Professorship and the Wu Family Research Fund.

\section{Compliance with Ethical Standards}

Conflict of Interest The authors have no conflict of interest to declare.

Human and Animal Rights and Informed Consent This article does not contain any studies with human or animal subjects performed by any of the authors.

\section{References}

Papers of particular interest, published recently, have been highlighted as:

- Of importance

•- Of major importance

1. Dong E, Du H, Gardner L. An interactive web-based dashboard to track COVID-19 in real time. Lancet Infect Dis. 2020;20(5):533-4.

2. Zaim S, Chong JH, Sankaranarayanan V, Harky A. COVID-19 and multiorgan response. Curr Probl Cardiol. 2020;45(8):100618.

3. Xu X, Chen P, Wang J, Feng J, Zhou H, Li X, et al. Evolution of the novel coronavirus from the ongoing Wuhan outbreak and modeling of its spike protein for risk of human transmission. Sci China Life Sci. 2020;63(3):457-60.

4.- Gupta A, et al. Extrapulmonary manifestations of COVID-19. Nat Med. 2020;26(7):1017-32 An important review of effects of COVID-19 on organ systems other than the lungs.

5. Guo T, Fan Y, Chen M, Wu X, Zhang L, He T, et al. Cardiovascular implications of fatal outcomes of patients with coronavirus disease 2019 (COVID-19). JAMA Cardiol. 2020;5(7):811-8.

6. Clerkin KJ, Fried JA, Raikhelkar J, Sayer G, Griffin JM, Masoumi A, et al. COVID-19 and cardiovascular disease. Circulation. 2020;141(20):1648-55.

7. Fried JA, Ramasubbu K, Bhatt R, Topkara VK, Clerkin KJ, Horn E, et al. The variety of cardiovascular presentations of COVID-19. Circulation. 2020;141(23):1930-6.

8. Madjid M, et al. Potential effects of coronaviruses on the cardiovascular system: a review. JAMA Cardiol. 2020.

9. Tian S, Xiong Y, Liu H, Niu L, Guo J, Liao M, et al. Pathological study of the 2019 novel coronavirus disease (COVID-19) through postmortem core biopsies. Mod Pathol. 2020;33(6):1007-14.

10. Wang C, Horby PW, Hayden FG, Gao GF. A novel coronavirus outbreak of global health concern. Lancet. 2020;395(10223):470-3.

11. Driggin E, Madhavan MV, Bikdeli B, Chuich T, Laracy J, BiondiZoccai G, et al. Cardiovascular considerations for patients, health care workers, and health systems during the COVID-19 pandemic. J Am Coll Cardiol. 2020;75(18):2352-71. 
12. Kazi DS, Martin LM, Litmanovich D, Pinto DS, Clerkin KJ, Zimetbaum PJ, et al. Case 18-2020: a 73-year-old man with hypoxemic respiratory failure and cardiac dysfunction. N Engl J Med. 2020;382(24):2354-64.

13. Wang D, Hu B, Hu C, Zhu F, Liu X, Zhang J, et al. Clinical characteristics of 138 hospitalized patients with 2019 novel coronavirus-infected pneumonia in Wuhan, China. JAMA. 2020;323(11):1061-9.

14. Berman JP, Abrams MP, Kushnir A, Rubin GA, Ehlert F, Biviano A, et al. Cardiac electrophysiology consultative experience at the epicenter of the COVID-19 pandemic in the United States. Indian Pacing Electrophysiol J. 2020.

15. Gawalko M, et al. COVID-19 associated atrial fibrillation: incidence, putative mechanisms and potential clinical implications. Int J Cardiol Heart Vasc. 2020;30:100631.

16. Ambrus DB, Benjamin EJ, Bajwa EK, Hibbert KA, Walkey AJ. Risk factors and outcomes associated with new-onset atrial fibrillation during acute respiratory distress syndrome. J Crit Care. 2015;30(5):994-7.

17. Goyal P, Choi JJ, Pinheiro LC, Schenck EJ, Chen R, Jabri A, et al. Clinical characteristics of Covid-19 in New York city. N Engl J Med. 2020;382(24):2372-4.

18. January CT, Wann LS, Alpert JS, Calkins H, Cigarroa JE, Cleveland JC Jr, et al. 2014 AHA/ACC/HRS guideline for the management of patients with atrial fibrillation: a report of the American College of Cardiology/American Heart Association Task Force on practice guidelines and the Heart Rhythm Society. Circulation. 2014;130(23):e199-267.

19. Bhatla A, Mayer MM, Adusumalli S, Hyman MC, Oh E, Tierney A, et al. COVID-19 and cardiac arrhythmias. Heart Rhythm. 2020;17(9):1439-44.

20. Yamin M, Demili AU. Prevention of ventricular arrhythmia and sudden cardiac death in COVID-19 patients. Acta Med Indones. 2020;52(3):290-6.

21. Proietti R, Joza J, Essebag V. Therapy for ventricular arrhythmias in structural heart disease: a multifaceted challenge. J Physiol. 2016;594(9):2431-43.

22. Abrams MP, et al. Malignant ventricular arrhythmias in patients with severe acute respiratory distress syndrome due to COVID-19 without significant structural heart disease. Heart Rhythm Case Rep. 2020.

23. Annane D, Sébille V, Duboc D, le Heuzey JY, Sadoul N, Bouvier E, et al. Incidence and prognosis of sustained arrhythmias in critically ill patients. Am J Respir Crit Care Med. 2008;178(1):20-5.

24. Shao F, Xu S, Ma X, Xu Z, Lyu J, Ng M, et al. In-hospital cardiac arrest outcomes among patients with COVID-19 pneumonia in Wuhan, China. Resuscitation. 2020;151:18-23.

25. Parish DC, Goyal H, Dane FC. Mechanism of death: there's more to it than sudden cardiac arrest. J Thorac Dis. 2018;10(5):3081-7.

26. Long B, Brady WJ, Koyfman A, Gottlieb M. Cardiovascular complications in COVID-19. Am J Emerg Med. 2020;38(7):1504-7.

27. Iba T, Levy JH, Connors JM, Warkentin TE, Thachil J, Levi M. The unique characteristics of COVID-19 coagulopathy. Crit Care. 2020;24(1):360

28. Kashi M, Jacquin A, Dakhil B, Zaimi R, Mahé E, Tella E, et al. Severe arterial thrombosis associated with Covid-19 infection. Thromb Res. 2020;192:75-7.

29. Giudicessi JR, Roden DM, Wilde AAM, Ackerman MJ. Genetic susceptibility for COVID-19-associated sudden cardiac death in African Americans. Heart Rhythm. 2020;17(9):1487-92.

30. Rattanawong P, et al. Guidance on short-term management of atrial fibrillation in coronavirus disease 2019. J Am Heart Assoc. 2020;9(14):e017529 This manuscript summarizes considerations of antiarrhythmics usage for $\mathrm{AF}$ in the setting of acute COVID-19 infection.
31. Sorajja D, Munger TM, Shen WK. Optimal antiarrhythmic drug therapy for electrical storm. J Biomed Res. 2015;29(1):20-34.

32. Enriquez A, Liang J, Gentile J, Schaller RD, Supple GE, Frankel DS, et al. Outcomes of rescue cardiopulmonary support for periprocedural acute hemodynamic decompensation in patients undergoing catheter ablation of electrical storm. Heart Rhythm. 2018;15(1):75-80.

33. Mitacchione G, et al. Ventricular tachycardia storm management in a COVID-19 patient: a case report. Eur Heart J Case Rep. 2020;4(FI1):1-6.

34. Wang Y, Wang Z, Tse G, Zhang L, Wan EY, Guo Y, et al. Cardiac arrhythmias in patients with COVID-19. J Arrhythm. 2020;36(5): 827-36.

35. Cooper LT Jr, Blauwet LA. When should high-grade heart block trigger a search for a treatable cardiomyopathy? Circ Arrhythm Electrophysiol. 2011;4(3):260-1.

36. Al-Assaf O, Mirza M, Musa A. Atypical presentation of COVID-19 as subclinical myocarditis with persistent high degree atrioventricular block treated with pacemaker implant. Heart Rhythm Case Rep. 2020.

37. Haddadin FI, et al. A case of complete heart block in a COVID-19 infected patient. J Cardiol Cases. 2020.

38. Gupta MD, Qamar A, MP G, Safal S, Batra V, Basia D, et al. Bradyarrhythmias in patients with COVID-19: a case series. Indian Pacing Electrophysiol J. 2020;20(5):211-2.

39. Kir D, Mohan C, Sancassani R. Heart brake: an unusual cardiac manifestation of COVID-19. JACC Case Rep. 2020;2(9):1252-5.

40. Eneizat Mahdawi T, Wang H, Haddadin FI, al-Qaysi D, Wylie JV. Heart block in patients with coronavirus disease 2019: a case series of 3 patients infected with SARS-CoV-2. Heart Rhythm Case Rep. 2020;6(9):652-6.

41. Chinitz JS, Goyal R, Harding M, Veseli G, Gruberg L, Jadonath R, et al. Bradyarrhythmias in patients with COVID-19: marker of poor prognosis? Pacing Clin Electrophysiol. 2020;43(10):1199-204.

42. Azarkish M, Laleh far V, Eslami M, Mollazadeh R. Transient complete heart block in a patient with critical COVID-19. Eur Heart J. 2020;41(22):2131.

43. Kochav SM, Coromilas E, Nalbandian A, Ranard LS, Gupta A, Chung MK, et al. Cardiac arrhythmias in COVID-19 infection. Circ Arrhythm Electrophysiol. 2020;13(6):e008719.

44. Lau ST, Yu WC, Mok NS, Tsui PT, Tong WL, Cheng SWC. Tachycardia amongst subjects recovering from severe acute respiratory syndrome (SARS). Int J Cardiol. 2005;100(1):167-9.

45. Yu CM, Wong RS, Wu EB, Kong SL, Wong J, Yip GW, et al. Cardiovascular complications of severe acute respiratory syndrome. Postgrad Med J. 2006;82(964):140-4.

46. Olshansky B, Sullivan RM. Inappropriate sinus tachycardia. J Am Coll Cardiol. 2013;61(8):793-801 This systemic review summarizes recommendations for treatment of IST.

47. Lazzerini PE, Laghi-Pasini F, Boutjdir M, Capecchi PL. Cardioimmunology of arrhythmias: the role of autoimmune and inflammatory cardiac channelopathies. Nat Rev Immunol. 2019;19(1):63-4.

48. Page RL, Joglar JA, Caldwell MA, Calkins H, Conti JB, Deal BJ, et al. 2015 ACC/AHA/HRS guideline for the management of adult patients with supraventricular tachycardia. Circulation. 2016;133(14): $506-74$.

49. Agarwal AK, Garg R, Ritch A, Sarkar P. Postural orthostatic tachycardia syndrome. Postgrad Med J. 2007;83(981):478-80.

50. Raj SR. Postural tachycardia syndrome (POTS). Circulation. 2013;127(23):2336-42.

51. Schondorf R, Low PA. Idiopathic postural orthostatic tachycardia syndrome: an attenuated form of acute pandysautonomia? Neurology. 1993;43(1):132-7. 
52. Umapathi T, Poh MQW, Fan BE, Li KFC, George J, Tan JYL. Acute hyperhidrosis and postural tachycardia in a COVID-19 patient. Clin Auton Res. 2020.

53. Romero-Sanchez CM, et al. Neurologic manifestations in hospitalized patients with COVID-19: the ALBACOVID registry. Neurology. 2020;95(8):e1060-70.

54. Sheldon RS, Grubb BP II, Olshansky B, Shen WK, Calkins H, Brignole M, et al. 2015 heart rhythm society expert consensus statement on the diagnosis and treatment of postural tachycardia syndrome, inappropriate sinus tachycardia, and vasovagal syncope. Heart Rhythm. 2015;12(6):e41-63.

55. Maron BJ, Udelson JE, Bonow RO, Nishimura RA, Ackerman MJ, Estes NA 3rd, et al. Eligibility and disqualification recommendations for competitive athletes with cardiovascular abnormalities: task force 3: hypertrophic cardiomyopathy, arrhythmogenic right ventricular cardiomyopathy and other cardiomyopathies, and myocarditis: a scientific statement from the American Heart Association and American College of Cardiology. Circulation. 2015;132(22): e273-80.

$56 . \bullet$ Hendren NS, et al. Description and proposed management of the acute COVID-19 cardiovascular syndrome. Circulation. 2020;141(23):1903-14 This comprehensive manuscript proposes management considerations for treatment of cardiovascular disease in acute COVID-19 infection.

57. Raj SR, Black BK, Biaggioni I, Paranjape SY, Ramirez M, Dupont WD, et al. Propranolol decreases tachycardia and improves symptoms in the postural tachycardia syndrome: less is more. Circulation. 2009;120(9):725-34.

58. Hanash CR, Crosson JE. Emergency diagnosis and management of pediatric arrhythmias. J Emerg Trauma Shock. 2010;3(3):251-60.

59. Edelson DP, Sasson C, Chan PS, Atkins DL, Aziz K, Becker LB, et al. Interim guidance for basic and advanced life support in adults, children, and neonates with suspected or confirmed COVID-19. Circulation. 2020;141(25):e933-43.

60. Sanna G, Serrau G, Bassareo PP, Neroni P, Fanos V, Marcialis MA. Children's heart and COVID-19: up-to-date evidence in the form of a systematic review. Eur J Pediatr. 2020;179(7):1079-87.

61. Tavazzi G, Pellegrini C, Maurelli M, Belliato M, Sciutti F, Bottazzi A, et al. Myocardial localization of coronavirus in COVID-19 cardiogenic shock. Eur J Heart Fail. 2020;22(5):911-5.

62. Kim IC, Kim JY, Kim HA, Han S. COVID-19-related myocarditis in a 21-year-old female patient. Eur Heart J. 2020;41(19):1859.

63. Sawalha K, Abozenah M, Kadado AJ, Battisha A, al-Akchar M, Salerno C, et al. Systematic review of COVID-19 related myocarditis: insights on management and outcome. Cardiovasc Revasc Med. 2020.

64. $\mathrm{Lu} \mathrm{S}$, et al. Effectiveness and safety of glucocorticoids to treat COVID-19: a rapid review and meta-analysis. Ann Transl Med. 2020;8(10):627.

65. Prescott HC, Rice TW. Corticosteroids in COVID-19 ARDS: evidence and hope during the pandemic. JAMA. 2020;324:1292-5.

66. Mitrani RD, Dabas N, Goldberger JJ. COVID-19 cardiac injury: implications for long-term surveillance and outcomes in survivors. Heart Rhythm. 2020;17:1984-90.

67. Puntmann VO, et al. Outcomes of cardiovascular magnetic resonance imaging in patients recently recovered from coronavirus disease 2019 (COVID-19). JAMA Cardiol. 2020.

68. Yancy CW, Fonarow GC. Coronavirus disease 2019 (COVID-19) and the heart-is heart failure the next chapter? JAMA Cardiol. 2020.

69. Phelan D, Kim JH, Chung EH. A game plan for the resumption of sport and exercise after coronavirus disease 2019 (COVID-19) infection. JAMA Cardiol. 2020
70. Wu Q, Zhou L, Sun X, Yan Z, Hu C, Wu J, et al. Altered lipid metabolism in recovered SARS patients twelve years after infection. Sci Rep. 2017;7(1):9110.

71. Gautret P, Lagier JC, Parola P, Hoang VT, Meddeb L, Mailhe M, et al. Hydroxychloroquine and azithromycin as a treatment of COVID-19: results of an open-label non-randomized clinical trial Int J Antimicrob Agents. 2020;56:105949.

72. Fuster V, Varieur Turco J. COVID-19: a lesson in humility and an opportunity for sagacity and hope. J Am Coll Cardiol. 2020;75(20): 2625-6.

73. Giudicessi JR, Noseworthy PA, Friedman PA, Ackerman MJ. Urgent guidance for navigating and circumventing the QTcprolonging and torsadogenic potential of possible pharmacotherapies for coronavirus disease 19 (COVID-19). Mayo Clin Proc. 2020;95:1213-21.

74. Rosenberg ES, Dufort EM, Udo T, Wilberschied LA, Kumar J, Tesoriero J, et al. Association of treatment with hydroxychloroquine or azithromycin with in-hospital mortality in patients with COVID-19 in New York state. JAMA. 2020;323: 2493-502.

75. Geleris J, Sun Y, Platt J, Zucker J, Baldwin M, Hripcsak G, et al. Observational study of hydroxychloroquine in hospitalized patients with Covid-19. N Engl J Med. 2020;382(25):2411-8.

76. Cavalcanti AB, Zampieri FG, Rosa RG, Azevedo LCP, Veiga VC, Avezum A, et al. Hydroxychloroquine with or without azithromycin in mild-to-moderate Covid-19. N Engl J Med. 2020.

77. Effect of hydroxychloroquine in hospitalized patients with Covid19. N Engl J Med. 2020.

78. Capel RA, Herring N, Kalla M, Yavari A, Mirams GR, Douglas G, et al. Hydroxychloroquine reduces heart rate by modulating the hyperpolarization-activated current if: novel electrophysiological insights and therapeutic potential. Heart Rhythm. 2015;12(10): 2186-94.

79. Zhang M, Xie M, Li S, Gao Y, Xue S, Huang H, et al. Electrophysiologic studies on the risks and potential mechanism underlying the proarrhythmic nature of azithromycin. Cardiovasc Toxicol. 2017;17(4):434-40.

80. Wu KC, Zhang L, Haberlen SA, Ashikaga H, Brown TT, Budoff $\mathrm{MJ}$, et al. Predictors of electrocardiographic QT interval prolongation in men with HIV. Heart. 2019;105(7):559-65.

81. Wu KC, Bhondoekhan F, Haberlen SA, Ashikaga H, Brown TT, Budoff MJ, et al. Associations between QT interval subcomponents, HIV serostatus, and inflammation. Ann Noninvasive Electrocardiol. 2020;25(2):e12705.

82. Myerson M, et al. Prolonged QTc in HIV-infected patients: a need for routine ECG screening. J Int Assoc Provid AIDS Care. 2019;18: 2325958219833926.

83. Romero J, Husain SA, Kelesidis I, Sanz J, Medina HM, Garcia MJ. Detection of left atrial appendage thrombus by cardiac computed tomography in patients with atrial fibrillation: a meta-analysis. Circ Cardiovasc Imaging. 2013;6(2):185-94.

84. Lakkireddy DR, Chung MK, Gopinathannair R, Patton KK, Gluckman TJ, Turagam M, et al. Guidance for cardiac electrophysiology during the COVID-19 pandemic from the Heart Rhythm Society COVID-19 Task Force; Electrophysiology Section of the American College of Cardiology; and the Electrocardiography and Arrhythmias Committee of the Council on Clinical Cardiology. Am Heart Assoc Heart Rhythm. 2020;17(9):e233-41.

Publisher's Note Springer Nature remains neutral with regard to jurisdictional claims in published maps and institutional affiliations. 